\title{
Internet y los problemas de apre(he)nder
}

\author{
Alfredo Vizcarro Broto
}

\subsection{Resumen}

Crítica de las posibilidades que ofrecen los sistemas de información telemática centrada en trespuntos: la sobreabundacia de información referencial, el carácter informe de la masa informativa y el fracaso en la promesa de transparencia en el acceso a la información. Aunque la Internet será una excelente plataforma de comunicación, los sueños utópicos no se cumplirán debido a que la educación, la información y el conocimiento son instrumentos de la lucha por la competitividad y tienen un valor de cambio cada vez mayor. Por ello, la consolidación de la Red llegará de su conversión en un mercado de información.

Palabras clave: Internet. Crítica social.

\subsection{Abstract}

Critic of the possibilities that telematic information systems offer. Three points are considered: the overweight of referential information, the amorphous character of the informative mass and the failure of the promise for transparency. Although the Internet will be an excellent communication platform, utopian dreams will not be fulfilled, because education, information and knowledge are competitive tools and have an ever growing value of change. So the net will consolidate with its transformation in an information market.

Keywords: Internet. Social criticism.

\section{Paradojas referentes a Internet}

Ante la creencia generalizada y cotidiana de que hay cosas inamovibles, tales como la democracia, el mercado o el euro, esta comunicación quiere ser una reflexión irreverente, en el sentido etimológico de que no haga la reverencia, sobre uno de los grandes fenómenos de finales de siglo: Internet.

En el folleto de presentación de este tercer encuentro, bajo el título de "Objetivos" se puede leer que “(...) los sistemas de información electrónica, gracias a las redes informáticas, proporcionan una facilidad y una potencia de publicación, difusión y acceso a la información nunca conocidas en la historia de la 
Humanidad". Pues bien, creo que esa potencia que recoge el documento nunca llegará a concretarse de forma provechosa, es decir, la potencia no culminará en acto.

La exposición se estructura en torno a tres paradojas que se producen actualmente en Internet:

- Información referencial vs. Información sustancial

- Individualidad vs. Gran masa informativa

- Transparencia deseada vs. Ocultación real

\section{Primera paradoja: Información referencial vs. Información sustancial}

Cualquier usuario de Internet sabe que la práctica totalidad de información ubicada en la red es meramente referencial. No en vano la posibilidad del enlace (la versión electrónica del Véase de toda la vida) es lo que más deslumbra en la red. Sin embargo ese espejismo de exhaustividad no se traduce en hallazgos sustanciosos. Por ejemplo, para desarrollar esta comunicación sólo me he valido de dos referencias que se hallan en la red. Es decir, si no hubiera consultado las fuentes impresas, no habría llevado a cabo este trabajo que usted está leyendo.

Así, se constata que el conocimiento, entendido éste como el procesamiento de información que nos conduce al progreso, no se puede conseguir actualmente en Internet. ¿Porqué? Porque la información que produce desarrollo cuesta mucho dinero. Porque la investigación y el mantenimiento de esta información cuesta más dinero. Porque, además, el valor añadido de esta información reside muchas veces en el secreto; o sea, en que solamente un reducido círculo de personas tenga acceso a ella.

Por todo ello, puede formularse la siguiente pregunta pregunta: ¿Está algún gestor de información dispuesto a quitarse el pan de la boca, es decir, la información privilegiada a la que tiene acceso, para satisfacer la sed de conocimiento de otra persona en aras de la difusión universal? En una época en que el mercado es el paradigma sería llevarnos a engaño contestar afirmativamente.

\section{Segunda paradoja: Individualidad vs. Gran masa informativa}

La navegación suele ser individual y no tiene visos de cambiar por dos razones fundamentales: comerciales y sociales. En cuanto a las comerciales, porque está claro que vale más la pena vender 6 unidades de cualquier producto informático que sólo 2 unidades. En cuanto a las sociales, porque el individuo es la razón de ser en la posmodernidad. Recordemos que hay pensadores que manifiestan que han muerto las ideologías, los movimientos colectivos e incluso la historia. 
En este tipo de navegación individual, el boca-oído es la forma más común de exploración conjunta. Los bookmarks se nos amontonan y terminan solapándose. Además, siempre tenemos un límite de tiempo de consulta (por imperativo del reloj y del bolsillo) y estamos ante un universo en expansión, un universo que es finito pero inabarcable.

¿Cómo resolvemos esta situación? ¿Cómo poner orden a esta masa informativa que, como dice García Gutiérrez, tiende a la entropía, al desorden, al caos? Ante tal dilema se presentan dos soluciones:

$1^{\text {a }}$ El hallazgo y el uso generalizado de posibilidades de búsqueda cada vez más sofisticadas (por ejemplo, la etiqueta Meta name en el lenguaje HTML, la mejora de los lenguajes de interrogación o el desarrollo de sistemas de búsqueda pasiva).

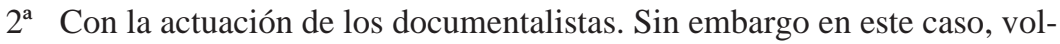
viendo a retomar lo dicho en la primera paradoja, cabe preguntarse: ¿Habrá alguien dispuesto a pagar los servicios de un profesional que no podrá hallar información valiosa? (Que sí será relevante desde el punto de vista de la búsqueda, pero no será beneficiosa desde el punto de vista económico).

\section{Tercera paradoja: Transparencia deseada vs. Ocultación real}

Frente a los utópicos que pensaban que un universal acceso conllevaría una universal apertura y un aumento de la transparencia, la democratización y la participación ciudadana, pocas organizaciones están dispuestas a desvelar completamente sus fines, procedimientos y actividades. Póngase el ejemplo que se desee: un gobierno, una multinacional, un departamento de investigación.

Para abundar sobre ello valgan como muestra unos ejemplos personales:. En el primer caso, mandé un mensaje al correo electrónico del Congreso de los diputados quejándome por la imposibilidad de presentarse diplomados de biblioteconomía a unas becas de colaboración en la biblioteca y solicitando una aclaración sobre tal impedimento; la respuesta que obtuve no contenía ninguna explicación, únicamente me agradecía haber usado su servicio de correo. Ante tal éxito ya no he vuelto a usarlo.

En el segundo caso, por motivos laborales debía hallar recursos informativos en la red sobre compañías aéreas: Pues bien, no hallé ninguna compañía de las importantes que hubiera incluido en su web la memoria anual de la empresa, algo que en papel se consigue relativamente fácil.

En realidad, volvemos a lo tratado anteriormente: el secreto es valor añadido y ninguna organización lo quiere perder. 


\section{8}

Por otro lado, y curiosamente, se produce el hecho contrario: Consciente o inconscientemente, los individuos cada vez tenemos menos intimidad, cada vez estamos más controlados por la modernización. Por ejemplo, por un solo número, el de la tarjeta de crédito, se puede saber qué productos consumimos más el fin de semana, qué gustos literarios tenemos o adonde vamos a veranear durante las vacaciones.

\section{Reflexiones finales}

Después de plantear estas tres paradojas, mi creencia es que Internet seguirá siendo un fantástico foro de discusión, una platea desde donde otear como está el mundo, una especie de ágora cibernética, en la que, sin embargo, el conocimiento no fructificará. Para que el conocimiento fructifique se deberá estar en posesión de dos capitales fundamentales: el capital intelectual (con estructuras adquiridas fuera de la red, a través del binomio educación/formación) y el capital monetario, que dará la capacidad de comprar información, surgiendo así una nueva Internet que perseguirá el Negocio en vez de la Divulgación, donde la gratuidad será un recuerdo de los locos años 90 . El resultado final es una cuarta paradoja: la supervivencia de la red llegará por la consolidación de un fin totalmente contrario al que posibilitó el desarrollo de Internet, es decir, negocio vs. divulgación.

Y así, treinta años después de mayo del 68, el espacio de utópica virtualidad, donde se creía que la libertad y el conocimiento no tenían límites, se vislumbra que toca a su fin. El poderoso caballero don dinero arrasa y crea nuevas realidades. Quizá haya que desembarazarse del concepto de aldea global (un concepto muy manido pero no tan equivocado, ya que el conocimiento se desarrolló en las ciudades, pero este es otro tema) y haya que recuperar la idea del Gran Hermano de Orwell.

Y acabo así el escrito trazando un círculo, tal vez melancólico, con la misma pregunta que daba pie a esta reflexión: ¿Alguien cree que la potencia de publicación, difusión y acceso a la información, que no sea referencial, se convertirá en acto?

\section{Bibliografía}

Cebrián, Juan Luis (1998). La red. Madrid : Taurus, 1998.

Codina, Lluís (1997). Cómo funcionan los servicios de búsqueda en Internet. // IWE. 6 : 5 (1997).

Cornella, Alfons. Extra!-Net. URL=<http://www.extra-net.net>.

Cornella, Alfons (1994). Los recursos de Información. Madrid : McGraw-Hill, 1994.

Currás, Emilia (1995). Concierto y desconcierto en la organización del conocimiento actual y su intersección con el mundo de la información. // Scire. 1:1 (en.-jun., 1995). 
García, Fernando (1998). Publicar en Internet. Madrid : Ra-Ma, 1998.

Martín, Pedro (1997). Información on-line e Internet para la Empresa. // Curso de la Sedic. (Mayo 1997).

Orwell, George (1984). Barcelona : Círculo de Lectores, 1984. 